\section{The development of an outreach training programme in orthodontics}

\author{
R. J. Cure ${ }^{1}$ and R. S. Ireland ${ }^{2}$
}

IN BRIEF

- Outreach programmes allow the treatment of patients in a localised primary care environment during student training.

- The training of students together on different but related courses encourages the team approach and can develop a better understanding of the individual roles of each team member.

- Outreach training can present challenges for both funding and the integration of course design and delivery.

\begin{abstract}
Objective To describe the establishment of an outreach centre for the training of all members of the orthodontic team. The development of the orthodontic team The remit of orthodontic nurses and orthodontic therapists is described and how their training may be delivered and integrated within a primary care training centre. Outreach training The reasons for the development of outreach training are discussed and how these are particularly relevant for the development of orthodontic training in the UK. The University of Warwick orthodontic outreach centre This has been established in Leamington Spa in comprehensively equipped premises providing seven surgeries, a lecture theatre, clinical skills laboratory, and technical support. It currently provides an MSc course in orthodontics for general dental practitioners (GDPs) and training for qualified dental nurses leading to the award of an Orthodontic Nurse's Certificate. It has also recently been approved by the General Dental Council (GDC) for the delivery of a course leading to the Diploma in Orthodontic Therapy commencing in July 2008.
\end{abstract}

\section{Introduction}

Traditionally orthodontics is introduced into the dental curriculum as part of the first five years of the undergraduate degree course, training students on qualification primarily to be able to identify patients requiring potential orthodontic therapy and when to refer them for specialist treatment. On being awarded their degree, those students wishing to specialise in orthodontics are required to undertake an approved course of postgraduate training traditionally delivered by a university within a dental school environment.

Some postgraduate deaneries have short training programmes for general dental practitioners who hold hospital appointments as orthodontic clinical assistants, but these do not lead to a

\footnotetext{
1;2Postgraduate Dental Education Unit, Institute of Clinical Education, Warwick Medical School, The University of Warwick, Coventry CV4 7AL ${ }^{*}$ Correspondence to: Dr Richard Cure Email: richard.cure@warwick.ac.uk
}

\section{Refereed Paper}

Accepted 23 April 2008

DOI: $10.1038 /$ sj.bdj.2008.463

${ }^{\oplus}$ British Dental Journal 2008; 204: 631-634 specialist qualification on completion of the programmes.

With the development of the dental team and the importance of delivering dental care by means of a team approach, it has been recognised that the specialist orthodontist will benefit from the support of team members specifically trained to assist in the provision of orthodontic care. In addition to which, the need for developing new training courses in orthodontics was identified many years ago, ${ }^{1}$ and this approach may go some way towards addressing the current problem of a shortage of suitably qualified and experienced providers of orthodontic treatment in the UK. ${ }^{2,3}$

Qualified dental nurses can undertake a course of study leading to a Certificate in Orthodontic Nursing awarded by the National Examining Board for Dental Nurses (NEBDN). This enables them to develop their knowledge, understanding and skills to provide appropriate clinical chairside support within the remit defined by the General Dental Council (Table 1).

The GDC has recently approved a new type of dental care professional (DCP) - the orthodontic therapist - and has endorsed the role of orthodontic

Table 1 The remit of the orthodontic
nurse
- A knowledge and understanding of
orthodontic problems and their management
- Take impressions for diagnostic models
- Pour and prepare diagnostic casts from
impressions
- Provide clinical chairside support for the
orthodontic specialist
- Provide appropriate maintenance advice on
the care of orthodontic appliances
- Provide oral hygiene and dietary advice for the
orthodontic patient
- Take clinical photographs

Table 2 The remit of the orthodontic therapist

- To undertake the cleaning and polishing of teeth and removal of supragingival deposits

- Take impressions and clinical photographs

- Take bite registration

- Undertake the placement, maintenance, and removal of orthodontic appliances under the direction of the orthodontic specialist

- Fit space maintainers, retainers and orthodontic headgear

- Undertake emergency care by relieving pain or making appliances safe

- Undertake all the duties of the orthodontic nurse 
therapists in its document Developing the dental team. ${ }^{4}$ The remit of the orthodontic therapist is clearly defined within regulations laid down by the GDC (Table 2).

Whilst the training of orthodontic nurses is now well established throughout the UK, the training of orthodontic therapists has only recently been initiated with the first course being run at Leeds Dental Institute. ${ }^{5}$

\section{Why develop outreach training?}

Outreach teaching, sometimes described as extramural or community-based placements, involves the delivery of education and training at sites remote from the core institution of learning. In dentistry, this means teaching and clinical practice carried out at sites located away from a dental school or hospital.

The vast majority of orthodontic treatment in the UK is currently carried out in a primary care environment and yet undergraduate and postgraduate training in orthodontics has traditionally taken place in the secondary care environment of dental schools and hospital clinics. The GDC has stated that DCPs should be able to train as part of the dental team and the training of DCPs should be more flexible, both in terms of the time allowed for the delivery of the courses, namely part-time options, and also in the environment where the education is delivered. ${ }^{4}$ The document discusses the extended clinical environment and outreach teaching and states that DCP students may work in approved outreach centres under the supervision of appropriately recognised teachers.

It has been suggested that outreach teaching delivers better value for money. For example, in Finland, all clinical undergraduate dental training over recent years has taken place in public dental service clinics, funded by state and local communities. ${ }^{6}$

With the development of the Internet, most reference books and journals are available online, thus removing the need for students to be based full-time within institutions with hard copy reference books and journals, which may only be accessed for a limited number of hours per day.

Evidence from a survey of dental therapists trained at the University of
Birmingham Dental School showed that, having been trained in a secondary care environment, they had problems with the transition into primary care workplaces. ${ }^{7}$ If training is carried out in a primary care setting, then such transition problems should not occur.

There is already a shortage of teaching staff in many dental schools and it is becoming ever more difficult to recruit high quality lecturers dedicated to a teaching career. The development of vocational training and the participation of general and specialist practitioners in both undergraduate and postgraduate education have demonstrated an extensive resource of skilled teachers. An infrastructure of orthodontic practices exists where specialists have shown an enthusiasm to participate in educational initiatives. Expanding their role into teaching would be an innovative use of both these specialists and their well equipped practices. Such a model exists in Bavaria and has been shown to be extremely successful. ${ }^{8}$

Options for change ${ }^{9}$ proposed that future dental education should focus on developing the skills needed in clinical practice, with an increased use of primary care outreach schemes to develop the training of both undergraduates and DCPs. Findings from research into outreach programmes encourage their development. ${ }^{10,11}$ The concept of outreach teaching in dentistry is not new. Outreach undergraduate training programmes have been developed in both the NHS community (salaried) dental service clinics, run by primary care trusts $^{12}$ and in the personal dental service. $^{13}$ Video-conference links have been established for general dental practitioners to provide continuing professional development and remote patient assessment. ${ }^{14}$ Some specialist training in both the UK and Sweden is carried out at nondental hospital sites, such as publiclyfunded clinics and/or hospitals..$^{15,16}$

In Germany, a significant amount of postgraduate specialist orthodontic training is carried out in specialist practices. ${ }^{8}$

There is widespread acceptance of the benefit of the team approach to delivery of oral healthcare, with the dentist occupying the position of leader of the team. It is logical therefore that training should also adopt a team approach. Such team training has been difficult to establish in dental schools but has been easier to deliver in primary care settings, where historically delivery of care has been largely team based. Orthodontics is no exception to this; indeed the recent addition of orthodontic therapists in the UK will promote further team development. This model of care has been successful for many years in North America. ${ }^{17}$

The document Options for change ${ }^{9}$ clearly lays down opportunities for educational progression outside the traditional dental hospital environment and the successful dental vocational training schemes have shown the value of dental education in a primary care setting.

Since not only orthodontic but most clinical dental care in the UK is delivered in a primary care environment, it could be argued that this would be the most appropriate and beneficial environment to develop both education and training. A number of potential benefits for students of training in a primary care environment have been identified ${ }^{18}$ and these can include:

- Contact with patients in their own environment

- Exposure to a wider variety of patients and clinical procedures

- Contact with healthcare workers outside the field of dentistry

- Development of a team approach and the application and development of time management skills

- Improved communication skills

- First-hand experience of health and social issues in the primary care environment and unrestricted by the artificial environment of a dental school or hospital

- Improved operator confidence and efficiency

- A broader understanding of the role of dentistry in establishing, maintaining and developing the health of the patient.

Many dental schools are experiencing problems in finding sufficient patients to provide students with appropriate clinical teaching material. This is largely because of the requirements for patients often to undertake time consuming and 
costly travel in order to access the centres. This can be particularly difficult when it involves young children or teenagers accompanied by an adult. In addition to which, children generally prefer to be treated in a more familiar and locally situated less threatening community environment. This is particularly relevant in the context of orthodontics.

\section{Development of outreach training}

The University of Warwick has established an outreach centre at Leamington Spa, known as the Leamington Spa Orthodontic Centre, which has been approved for the provision of the National Examining Board for Dental Nurses (NEBDN) Certificate in Radiography, the NEBDN Certificate in Orthodontic Nursing and the MSc course in Orthodontics. It has also recently been provisionally approved by the General Dental Council for the delivery of a course leading to the Diploma in Orthodontic Therapy commencing in July 2008. The centre is housed within a six storey Regency building with its own large car park in the centre of Leamington Spa, seven miles from the University of Warwick. Its facilities have been developed specifically for teaching and include a fully equipped lecture suite seating up to 30 students, with a camera/video link to a surgery within the building, enabling hands-on style demonstrations to be delivered to the lecture theatre of all types of clinical procedures. A clinical skills laboratory is also linked to the lecture theatre and surgery. Video-conferencing allows off site links to other similar facilities worldwide. There is a library with an extensive selection of both journals and reference books, computer and Internet access, including access to The University of Warwick library. Comprehensive clinical and technical facilities are also available. The Centre has Investors in People accreditation.

Each course is delivered as a separate, 'stand-alone' training programme in its own right, providing education to prepare students for their external assessments by either the NEBDN or The University of Warwick. The NEBDN nursing certificate course held at the centre is well established and the MSc programme is now in its second year.

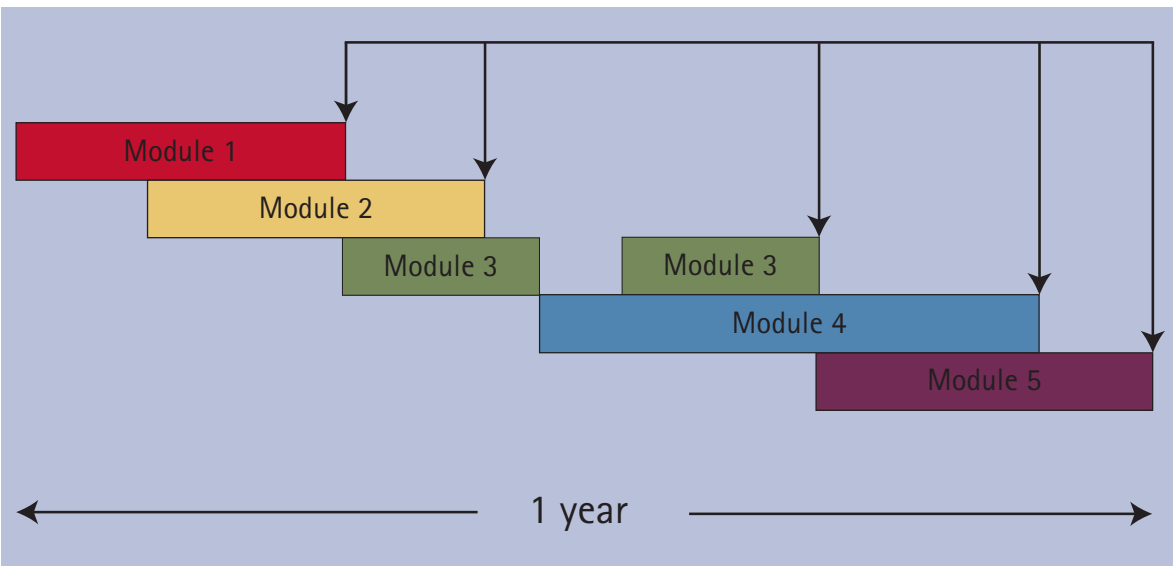

Fig. 1 Orthodontic therapy course modular structure

The MSc programme has an annual intake of 30-40 students and the course is delivered over three years, with the option for students to take a maximum of eight years to complete the MSc. The first year comprises ten core teaching days with further flexible sessions within clinical practice. Year 2 comprises three modules, including a module in clinical practice, which by the nature of orthodontic treatments, will realistically take a minimum of two years to complete. The third year includes a research project.

The orthodontic nurses course is a six month course beginning in June and December each year. Each intake consists of a maximum of ten students. There are nine teaching days with theoretical, laboratory and clinical aspects of orthodontic nursing fully covered. Students are able to attend for extra clinical experience in addition to the timetabled sessions if necessary. They each produce two patient portfolio log diaries as part of their preparation for the Certificate. The training leading to the orthodontic nursing certificate provides an excellent baseline of knowledge for students wishing to progress to the orthodontic therapy course.

The orthodontic therapist course will commence in July of each year starting in 2008 and will have an annual intake of ten students. It will consist of five overlapping modules delivered over 30 study days. At the conclusion of each module the students will undergo a summative assessment with the finals Diploma examination at the termination of the course (Fig. 1).

The study days will be distributed over the 12 months of the course with a greater number in the first two months. The study days are integrated with clinical practice gained at the students' own individual specialist practices or clinics.

The structure of each course is modular and although independent of each other, offer opportunities for overlap in terms of theoretical teaching and overall patient care. The integration of the clinical and classroom learning environments in which the students from all the courses are involved, promote the orthodontic team approach. Orthodontic nurses currently benefit greatly from clinical discussions with MSc students and in the future this will include orthodontic therapists. Certain skills, such as clinical photography and radiography, are mastered very successfully by orthodontic nurses; these skills can be passed on to the other students. A growing awareness and respect for the role of each and every member of the orthodontic team is developed, together with a greater appreciation of the complexities of other team members' responsibilities and roles.

\section{Student recruitment}

Demand for places on both the Orthodontic MSc course and the orthodontic nurses courses has been high and this is anticipated to continue. Initial studies suggest that there will be a high demand for orthodontic therapists largely because of the current orthodontic manpower requirements in the $\mathrm{UK}^{2}$ and the demand by orthodontists for appropriately trained support services. The proposed course has generated considerable local interest from qualified orthodontic 
nurses and it will be advertised in the dental press and websites.

\section{Staff provision}

In most UK teaching hospitals, part-time teachers are now playing a significant and valuable role in both undergraduate and postgraduate education. The GDC has also stated that, in the training of dental care professionals, the contribution of part-time clinical teachers, including those who work in general or community dental practice and hold appropriate qualifications, is highly advantageous. ${ }^{4}$

The University of Warwick has developed a training programme for all of its appointed teaching staff. It is a pre-requisite of the University that each member of staff has to complete this programme prior to teaching and to have annual re-accreditation. The University has both full-time educationalists and part-time members of its Postgraduate Dental Education Unit who have for many years developed dental education programmes for the Royal College of Surgeons of England and also acted as senior advisers for bodies such as Denplan and primary care trusts.

\section{Potential barriers to outreach training}

Funding issues can be a significant problem. The set-up costs of equipping practices to provide clinical and nonclinical areas can be considerable. If funding of education is to continue from government sources, then as training moves from the secondary to the primary care sector, some of this will need to be diverted from secondary care educational institutions into primary care locations. This could present problems for existing dental school models.

Many students, if funding their own education, will demand the greater flexibility of training offered by institutions that base their teaching at outreach centres, to enable them to continue to maintain their practices and income stream during their postgraduate education.

Students who are prepared to pay course fees which result in a non-registerable qualification may be attracted to a course that lacks the appropriate quality assurance. Fortunately courses run under the auspices of an awarding authority such as a University or the Royal College of Surgeons have well established quality assurance protocols. The General Dental Council plays an important role in overseeing the development and ongoing delivery of all academic courses leading to a registerable qualification.

There may be additional problems arising from the logistical difficulties of delivering programme teaching integration and it is anticipated that these would be identified by the planned retrospective course evaluation by the University Department of Education.

\section{Conclusion}

The University of Warwick orthodontic outreach development offers an exciting opportunity to provide a potential model for future orthodontic training in the UK. The integration of the training of all members of the orthodontic dental team in a primary care setting, quality assured in all aspects of provision is an innovative approach.

1. The joint response of the British Orthodontic Societies to the Nuffield Inquiry into Personnel Auxiliary to Dentistry. Br J Orthod 1992; 19: 334-342.
2. Robinson P G, Willmott D R, Parkin N A, Hall A C Report of The Orthodontic Workforce Survey of The United Kingdom February 2005. Orthodontic Manpower Survey, 2005.

3. Sieminska-Piekarczyk B, Adamidis JP, Eaton K A, McDonald J P, Seeholzer H. A survey of perceived problems in orthodontic education in 23 European countries. J Orthod 2000; 27: 343-348.

4. General Dental Council. Developing the denta team. Curricula Frameworks for Registerable Qualifications for Professionals Complementary to Dentistry. September 2004

5. Jenkins F. New orthodontic course: a route to registration. Faculty of General Dental Practice (UK) The Royal College of Surgeons of England. Team in Practice 2007; 4: 8-9.

6. Opecusministeria Hammasklinikkatyaryhman Muistio (Memorandum from Working Group on Clinical Training of Dental Students Outside Dental Schools, 997) Report no 10. Helsinki, Finland: Ministry of Education; 1997. (English Summary).

7. Firmstone V. How the newly qualified therapists complement the NHS dental team. West Midlands Workforce Deanery and the Centre for Research in Medical and Dental Education, University of Birmingham annual educational conference, Aston University 17 May 2007.

8. McDonald J P, Adamidis J, Eaton K A, Seeholzer H, Sieminska Piekarczyk B A. Survey of postgraduate (specialist) orthodontic education in 23 European countries. J Orthod 2000; 27: 88-94.

9. Department of Health. NHS dentistry: options for change. London: Department of Health 2002.

10. Smith $M$, Lennon M A, Brook A H, Blinkhorn FA, Blinkhorn A S, Robinson P G. A randomised controlled trial of the effect of outreach placement on the treatment planning of dental students. BrDent J 2006; 201 (Suppl): 27-31.

11. Bailit H. Community-based clinical education programs. Major findings and recommendations. J Dent Educ 1999; 63: 981-989.

12. Elkind $A$, Watts $C$, Qualtrough $A$, Blinkhorn A S et al. The use of outreach clinics for teaching undergraduate restorative dentistry. Br Dent J 2007; 11: 127-132.

13. Lennon M A, Ireland R S, Tappin J, Ratcliffe P M et $a l$. The personal dental service as a setting for an undergraduate clinical programme. Br Dent J 2004; 10: 419-422.

14. Cook J, Mullings C, Vowles R, Ireland R S, Stephens C D. On line orthodontic advice. A protocol for a pilot teledentistry system. J Telemed Telecare 2001; 7: 324-333.

15. Feldman C A, Saporito R A, Cinotti W et al. Educating dentists in community-based settings. Can J Community Dent 1997; 12: 15-21.

16. Elkind A. Outreach teaching: is this the future for dental education? Br Dent J 2002; 193: 1-2.

17. Pollard T. Orthodontic therapists - the current situation. J Orthod 2000; 27: 207-209.

18. Eaton K A. Outreach teaching - coming soon to a practice near you. Prim Dental Care 2005; 12: 115-116. 